\title{
Calificación del origen de la enfermedad y del accidente de trabajo biológico por SARS-CoV-2 (COVID-19)
}

\section{Qualification of the origin of the disease and biological work accident by SARS-CoV-2 (COVID-19)}

\author{
Santiago Acosta Ortiz \\ Especialista en Medicina Laboral y del Trabajo \\ Universidad de Antioquia, Colombia \\ santiago.acostao@udea.edu.co
}

\section{Resumen}

La pandemia por COVID-19 afecta a muchos trabajadores y a sus familias, lo que hace necesario un procedimiento de calificación de origen que responda a los aspectos clínicos de la enfermedad, así como los aspectos jurídicos relativos a la calificación del origen. Para lo anterior, este artículo propone un acercamiento al problema luego de identificar varias ocupaciones de riesgo, en especial, aquellas del sector salud. Quienes laboran en este último ámbito han sido incluidos como beneficiarios del concepto de enfermedad laboral directa, sin requerir una calificación para acceder a las prestaciones del sistema general de riesgos laborales. También, es posible determinar la infección por COVID-19 como consecuencia de un accidente de trabajo biológico, siendo necesario documentar un evento súbito debidamente reportado a la ARL. Finalmente, existen unas responsabilidades claramente determinadas para todos los actores, incluyendo empleadores, IPS, EPS y ARL.

1 Artículo de reflexión. 


\section{Palabras clave}

Coronavirus; Calificación del origen; Enfermedad laboral; Exposición ocupacional; Accidente de trabajo.

\section{Abstract}

The COVID-19 pandemic affects many workers and their families, which makes necessary an origin qualification procedure that responds to clinical aspects of the disease, as well as the legal aspects related to the qualification of origin.

Hence, this article proposes an approach to the problem after identifying many occupations of risk, especially those in the health sector.

Those who work in this last area, have been included as beneficiaries of the direct occupational disease concept without requiring a categorization to access the benefits of the occupational risk general system.

It is also possible to determine the COVID-19 infection because of a biological work accident, being necessary to document a sudden event duly reported to the ARL.

Finally, there are a clearly defined liabilities stated for everybody involved including employers, IPS, EPS, and ARL (respectively: Institutional Health Service Provider, Health Care Provider, and Labor Risk Administration, all for their acronym in Spanish)

\section{Keywords}

Coronavirus, qualification of origin, occupational disease, occupational exposure, work accident.

Cómo citar este artículo:

Acosta, A. (2021). Calificación del origen de la enfermedad y del accidente de trabajo biológico por SARS-CoV-2 (COVID-19). Revista de la Facultad de Derecho y Ciencias Políticas, 51 (134), pp. 290 - 302. doi: https://doi.org/10.18566/rfdcp.v51n134.a12

Recibido: 08 de marzo de 2020.

Aprobado: 09 de noviembre de 2020. 


\section{Introducción}

La calificación del origen de la enfermedad producida por el nuevo coronavirus COVID-19 constituye la puerta de entrada que permite el acceso a las prestaciones asistenciales o económicas derivadas de las contingencias cubiertas por el Sistema General de Riesgos Laborales a través de las administradoras de riesgos laborales (ARL) (Acosta \& Cúellar, 2019, p. $4)$.

Si bien el Sistema Integral de Seguridad Social debe asegurar la atención integral de todos los trabajadores mediante el sistema de salud, a través de las entidades promotoras de salud (EPS), la garantía de las prestaciones propias de los eventos de origen laboral exige un proceso de calificación oportuno y eficaz, especialmente cuando la contingencia se deriva de una pandemia que implica un importante riesgo de incapacidad temporal para los trabajadores contagiados, y una letalidad significativa que amenaza los ingresos de sus familiares sobrevivientes.

Por lo tanto, cobra especial importancia establecer y aplicar mecanismos que establezcan de una manera efectiva, el origen de la infección, para que los trabajadores y sus sobrevivientes puedan acceder al disfrute efectivo de las prestaciones asistenciales $\mathrm{y}$, en especial, las prestaciones económicas, cuando esta enfermedad encuentre su origen en los riesgos causados y ocasionados por el trabajo.

A continuación, se presenta una propuesta que busca facilitar el entendimiento y las acciones que deben realizar los diferentes actores frente a la calificación del origen de la COVID-19, que integra aspectos jurídicos y clínicos claves para este proceso.

\section{Principales sectores y ocupaciones de riesgo}

El riesgo ocupacional de contraer una infección por COVID-19 dependerá de variables como el sector económico, contacto estrecho con otras personas, medidas de protección y medios de transporte utilizados en el ámbito laboral (OSHA, 2020, p. 18).

Esta enfermedad tiene como principal población de riesgo a todos aquellos trabajadores de la salud y de otras áreas que presten sus servicios dentro de instituciones prestadoras de salud (IPS) de manera presencial, incluyendo 
médicos, enfermeras y auxiliares de enfermería, bacteriólogos, odontólogos, técnicos de laboratorio y ayudas diagnósticas, camilleros, vigilantes, y todo el personal administrativo y de apoyo que tenga contacto con pacientes con sospecha o confirmación de COVID-19, o con elementos que puedan servir de repositorio del virus.

En un segundo nivel se encuentran los trabajadores de morgues, funerarias, cementerios, transporte terrestre o aéreo, y todos los que tengan contacto o atención directa al público.

\section{Accidente de trabajo (AT)}

Durante la fase inicial de la pandemia en Colombia, el Gobierno Nacional ha definido protocolos para la calificación del origen de la COVID-19, indicando rutas para calificar una potencial infección como accidente de trabajo (AT) ${ }^{2}$. Sin embargo, es fundamental reconocer el mecanismo de transmisión de la enfermedad, así como las características fisiopatológicas y epidemiológicas para poder concluir que esta infección se trata de un AT. Para aclarar lo anterior se debe verificar si la infección puede enmarcarse en la definición del Artículo 3 de la Ley 1562 de 2012: "Es accidente de trabajo todo suceso repentino que sobrevenga por causa o con ocasión del trabajo, y que produzca en el trabajador una lesión orgánica, una perturbación funcional o psiquiátrica, una invalidez o la muerte (...)” (subrayado fuera del texto).

La infección por COVID-19 en el escenario de pandemia, con circulación comunitaria del virus, implica que, en la mayoría de los casos, se desconoce la fuente del contagio, el cual se explica usualmente por la exposición a microgotas de saliva de personas infectadas, pero también al contacto con superficies o elementos contaminados con saliva o fluidos corporales (por ejemplo, pasamanos y barandas), sin que se pueda identificar el momento exacto del contagio, dando lugar al desarrollo de una infección, asintomática o con síntomas, de manera paulatina y no súbita.

Sin embargo, es posible que un evento súbito que dé lugar a un accidente de trabajo biológico (punciones y contacto en mucosas o piel lesionada con

2 Ministerio de Salud y Protección Social. Lineamientos para prevención, control y reporte de accidente por exposición ocupacional a la COVID-19 en instituciones de salud. Bogotá. Abril de 2020. 
fluidos corporales de un paciente sospechoso o confirmado para COVID-19) pueda desencadenar, luego de un periodo de incubación, una infección por coronavirus, y, en ese caso, se tendría que establecer como una consecuencia derivada de un AT. En este escenario, el empleador deberá reportar el evento súbito mediante el formato único de reporte de accidente de trabajo FURAT, para que el trabajador reciba la atención inicial del AT biológico (incluyendo pruebas para $\mathrm{VIH}$, hepatitis $\mathrm{B}$ y C) con seguimiento diario de síntomas y prueba RT-PCR al día 7 para confirmar o descartar la infección por COVID-19 (Ministerio de Salud y Protección Social, 2020, p. 12).

En consecuencia, se insiste en que, en la mayoría de los casos con exposición ocupacional, el origen deberá determinarse como enfermedad laboral, y los casos que se puedan enmarcar como un AT serían mínimos.

\section{Enfermedad laboral (EL)}

De acuerdo con el Artículo 4 de la Ley 1562 de 2012, se debe aceptar como enfermedad laboral:

La contraída como resultado de la exposición a factores de riesgo inherentes a la actividad laboral o del medio en el que el trabajador se ha visto obligado a trabajar. El Gobierno Nacional, determinará, en forma periódica, las enfermedades que se consideran como laborales y en los casos en que una enfermedad no figure en la Tabla de enfermedades laborales, pero se demuestre la relación de causalidad con los factores de riesgo ocupacional será reconocida como enfermedad laboral, conforme lo establecido en las normas legales vigentes.

De modo tal que, frente a la COVID-19, no se puede concluir que los trabajos o actividades con riesgo biológico sean los únicos que puedan dar lugar a una infección de origen laboral, ya que cualquier otra actividad que implique para el trabajador tener que ejecutar sus actividades en un medio que pueda permitir el contagio, conlleva a que esa ocupación deba considerarse como un oficio de riesgo. Lo anterior, en un contexto de pandemia y circulación comunitaria del virus, sería cualquier escenario de interacción cercana con otras personas.

Por lo tanto, el empleador deberá evaluar el riesgo de cada uno de sus trabajadores, y si se presenta un caso de infección por COVID-19, confirmado mediante prueba de laboratorio para un trabajador con riesgo ocupacional, 
se deberá notificar el evento mediante formato único de reporte enfermedad laboral (FUREL) a la EPS, ARL y a la entidad territorial ${ }^{3}$.

Frente al proceso para determinar el origen de cualquier enfermedad, se debe tener presente que en Colombia este ha de adelantarse por el cuerpo médico, especialista en seguridad y salud en el trabajo con licencia vigente, de acuerdo con la Resolución 4502 de 2012 del Ministerio de Salud y Protección Social $^{4}$ (Acosta \& Cuellar, 2019, p. 5), a través de dictamen (primera oportunidad o primera y segunda instancia por entidad competente ${ }^{5}$ ), o bien, por medio de providencia de un juez laboral en el marco de un proceso judicial ordinario.

\section{Enfermedad laboral directa}

Se trata de una definición surgida a partir de la tabla de enfermedades laborales adoptada mediante el Decreto 1477 de 2014 en la sección II, parte A, de su Artículo 1., en el cual se incluyeron inicialmente cuatro enfermedades (asbestosis, silicosis, antracosis y mesotelioma). El Artículo 4 del mencionado decreto estableció que, a partir del diagnóstico, el trabajador podrá acceder directamente a la atención en salud por parte de la ARL, haciendo efectiva la presunción de origen ${ }^{6}$ sin necesidad de un dictamen o calificación, a diferencia de las demás enfermedades incluidas en la sección B de la tabla de EL (enfermedades laborales presuntas no directas) y de las no incluidas en la tabla, las cuales requieren una calificación de origen para poder acceder a las prestaciones del Sistema General de Riesgos Laborales (SGRL).

Sin embargo, lo anterior no impide que la ARL y el empleador tengan la posibilidad de iniciar un proceso de calificación en primera oportunidad, aportando las pruebas que permitan desvirtuar la presunción de enfermedad laboral directa y, de esa manera, determinar que la enfermedad por COVID-19 sea de origen común, y, en ese caso, el trabajador tendría que volver a ser atendido a través de su EPS en condiciones del plan de beneficios en salud, PBS.

\footnotetext{
Según lo establecido por la Circular 17 de 2020 del Ministerio del Trabajo

Por medio de la cual se reglamenta la expedición y renovación de licencias de salud ocupacional.

Artículo 142 del Decreto 19 de 2012: EPS, ARL, AFP, Colpensiones, aseguradoras previsionales y juntas de calificación de invalidez.

6 Artículo 202 CST. Presunción de enfermedad profesional. Solamente las enfermedades contempladas en la tabla adoptada en el artículo anterior se presumen profesionales.
} 
Para poder incluir una nueva enfermedad dentro de la tabla de EL, así como para definirla como enfermedad laboral directa, el Gobierno Nacional debe proceder de acuerdo con los parágrafos $1 .^{\circ}$ y $2 .^{\circ}$ del Artículo 4 de la Ley 1562 de 2012, actualizando la tabla de enfermedades laborales:

Parágrafo $1{ }^{\circ}$. El Gobierno Nacional, previo concepto del Consejo Nacional de Riesgos Laborales, determinará, en forma periódica, las enfermedades que se consideran como laborales.

Parágrafo 2.․ Para tal efecto, El Ministerio de la Salud y Protección Social y el Ministerio de Trabajo, realizarán una actualización de la tabla de enfermedades laborales por lo menos cada tres (3) años atendiendo a los estudios técnicos financiados por el Fondo Nacional de Riesgos Laborales.

A pesar de estos requisitos, el Gobierno Nacional, haciendo uso de sus facultades extraordinarias otorgadas en el marco del estado de Emergencia Económica, Social y Ecológica, definió el nuevo coronavirus -COVID-19- como enfermedad laboral directa a través del Artículo 13 del Decreto Legislativo 538 de 2020, del Ministerio de Salud y Protección Social. Posteriormente, el Ministerio del Trabajo actualizó la tabla de enfermedades laborales, mediante el Decreto 676 de 2020, modificándola en dos puntos.

En primer lugar, la COVID-19 se incluyó de manera expresa en la parte A (enfermedades laborales directas) de la sección II (grupo de enfermedades del anexo técnico del Decreto 1477 d 2014) para los trabajadores de la salud y personal de apoyo o administrativo de las IPS, teniendo ahora cinco enfermedades laborales directas (asbestosis, silicosis, neumoconiosis, mesotelioma y COVID-19) y definiendo las ocupaciones a las que se les permite establecer la categoría de enfermedad laboral directa para cada uno de estos cinco diagnósticos bajo presunción legal.

En segundo lugar, se modificó el Artículo 4, estableciendo que, en adelante, las enfermedades laborales directas tendrán reconocimiento de las prestaciones asistenciales, y también de las prestaciones económicas, por parte del SGRL, desde el momento del diagnóstico médico de la enfermedad.

Por último, el Decreto 676 estableció que, de forma transitoria durante la emergencia sanitaria, las ARL deben asumir el costo de las pruebas diagnósticas $\mathrm{y}$ de tamizaje para COVID-19 realizadas a trabajadores del sector salud (incluyendo personal administrativo y de apoyo) reembolsando 
de manera directa el costo de las pruebas a las IPS, sin establecer la facultad u obligación para que las ARL recobren estas prestaciones a las EPS cuando las pruebas son negativas.

Para las ocupaciones asociadas a la enfermedad laboral directa, una vez se cuente con una prueba positiva para COVID-19 o cualquier medio de diagnóstico confirmado para las otras cuatro enfermedades laborales directas, el empleador deberá notificar la infección mediante el FUREL, y el trabajador podrá continuar recibiendo, de manera inmediata y sin necesidad de calificación, las prestaciones asistenciales (consultas, medicamentos, ayudas diagnósticas, terapias, hospitalización, etc.) y económicas (incapacidades temporales, incluyendo el ajuste retroactivo al 100 \% de las incapacidades de origen común ya reconocidas, indemnización en caso de incapacidad permanente parcial, auxilio funerario, pensión de invalidez y de sobreviviente en caso de muerte).

Para las demás ocupaciones no incluidas en el Artículo 13 del Decreto 538 de 2020, se requiere un proceso de calificación del origen para poder determinar que la infección por COVID-19 se trata de una EL.

\section{Responsabilidades de los empleadores}

En materia de la calificación del origen de la COVID-19, los empleadores deben cumplir las siguientes medidas:

1. Identificar el nivel de riesgo ocupacional de sus trabajadores

2. Realizar vigilancia epidemiológica y notificar a las entidades territoriales los casos positivos, estableciendo canales de comunicación con las autoridades de salud ${ }^{7}$.

3. Si se produce un AT biológico, notificar el caso mediante FURAT ${ }^{8}$ a la ARL y EPS, verificando que se realice seguimiento al trabajador para identificar si llegase a contraer COVID-19 como consecuencia del AT.

4. Ante un caso positivo, identificar si el trabajador tiene una ocupación de riesgo para COVID-19 y, de ser así, notificarlo mediante FUREL a la ARL y EPS. De manera paralela, se debe efectuar un cerco epidemiológico para identificar contactos estrechos, e informar a la ARL para que se realice

$7 \quad$ Según lo establecen las circulares 17 y 26 de 2020 del Ministerio del Trabajo colombiano.

8 Según lo establecido por la Resolución 156 de 2005 del Ministerio del Trabajo, mediante formato único de reporte e accidente de trabajo. 
seguimiento a cada uno de los contactos, quienes, en caso de resultar positivos deberán calificarse como EL.

5. Si la ocupación no es de las incluidas en el Artículo 13 del Decreto 538 de 2020, el caso deberá ser sometido a calificación de origen por la EPS o ARL y el empleador deberá aportar los soportes requeridos por la entidad (FUREL, contrato, certificado de cargos y labores, análisis de cargos y labores, análisis de puesto de trabajo, etc.).

6. Una vez sea notificado del dictamen de origen, decidir si lo acepta o interponer controversia para que el caso sea llevado a primera instancia ante la Junta Regional de Calificación de Invalidez o a segunda instancia ante la Junta Nacional de Calificación de Invalidez.

7. Acompañar y orientar al trabajador durante el proceso de atención y de calificación, evitando que dicho proceso dé lugar a un conflicto laboral que afecte la relación entre las partes.

\section{Responsabilidades de las IPS}

Además de hacer efectiva la atención médica a los trabajadores, las IPS tienen responsabilidades dentro del proceso de calificación del origen de la COVID-19, incluyendo aquellas establecidas por la Resolución 2569 de 1999 del Ministerio de Salud ${ }^{9}$ (parcialmente derogada).

1. Capacitación a todos sus profesionales frente a las guías y protocolos de diagnóstico, incluyendo COVID-19.

2. Capacitación básica a todos sus profesionales frente a la identificación y calificación del origen de las enfermedades, incluyendo COVID-19.

3. Disponer en cada consultorio y espacio de atención, los criterios, ocupaciones y exámenes clínicos que orienten la calificación del origen de las enfermedades, incluyendo COVID-19.

4. Fijar avisos en las áreas de espera que orienten a los trabajadores para informar o consultar cuando sospechen que tengan una enfermedad de origen laboral e informarles sobre las prestaciones a las cuales tienen derecho.

5. Informar a la EPS y ARL cuando se atienda un trabajador, cuya afección se sospecha de origen laboral.

9 Por la cual se reglamenta el proceso de calificación del origen de los eventos de salud en primera instancia, dentro del Sistema de Seguridad Social en Salud, en Colombia. 


\section{Responsabilidades de las EPS}

Más allá de garantizar el proceso de atención mediante su red de atención, las EPS deben disponer de un proceso de calificación oportuno y eficaz, con mecanismos que brinden información a sus afiliados. Igualmente, deben disponer de canales de comunicación con los prestadores que permitan identificar y captar los casos de posible origen laboral, para iniciar la calificación de origen y notificar el dictamen a todos los interesados. Es fundamental que las EPS realicen vigilancia epidemiológica de los trabajadores con COVID-19, pues hasta no contar con una prueba positiva, todos los casos se atienden en condiciones de enfermedad de origen común, y es la EPS la entidad que tendrá conocimiento de los casos confirmados para poder iniciar la calificación del origen en primera oportunidad, permitiendo, con ello, equilibrar la financiación de la pandemia entre el Sistema de Salud y el Sistema de Riesgos Laborales.

\section{Responsabilidad de las ARL}

Al igual que las EPS, las ARL deben disponer de mecanismos de calificación oportunos y de fácil acceso para los trabajadores con ocupaciones que impliquen un riesgo ocupacional por COVID-19, permitiéndoles acceder a una calificación de origen para esta enfermedad y, con ello, el acceso y disfrute de las prestaciones del SGRL.

Las ARL tienen responsabilidad especial en materia de prevención y asesoría a sus empresas afiliadas y a sus trabajadores durante todo el proceso previo y posterior a la calificación de los casos, estableciendo canales para informar y notificar casos con exposición ocupacional, sospechosos y confirmados.

A partir del diagnóstico con prueba positiva para COVID-19 en trabajadores del sector salud, las ARL deben garantizar la continuidad de la atención y el reconocimiento de las prestaciones económicas de origen laboral, mediante la definición de enfermedad laboral directa.

Durante la emergencia sanitaria, tanto las ARL como las EPS, deben facilitar sus procesos de calificación disponiendo mecanismos y canales virtuales para el envío y recepción de soportes, dictámenes y controversias. 


\section{Propuesta de la calificación del origen para la COVID-19}

A continuación se presenta un procedimiento para determinar el origen de COVID-19, de acuerdo con las definiciones técnicas vigentes a la fecha de este artículo, así como a los fundamentos jurídicos que rigen el proceso de determinación del origen de la enfermedad en Colombia, diferenciando el proceso para eventos súbitos que dan lugar a un accidente de trabajo biológico, de aquellos eventos de salud de aparición paulatina en los que se debe aplicar el proceso de calificación del origen de una enfermedad.

Este algoritmo de calificación debe aplicarse si se trata de un trabajador del sector salud, en cuyo caso simplemente se deberá notificar la enfermedad confirmada a la ARL y demás partes interesadas para su conocimiento y reconocimiento, o bien, si se trata de un trabajador de otro sector, para lo cual ha de seguirse el proceso de calificación del origen en primera oportunidad.

Proceso de calificación del origen para COVID-19

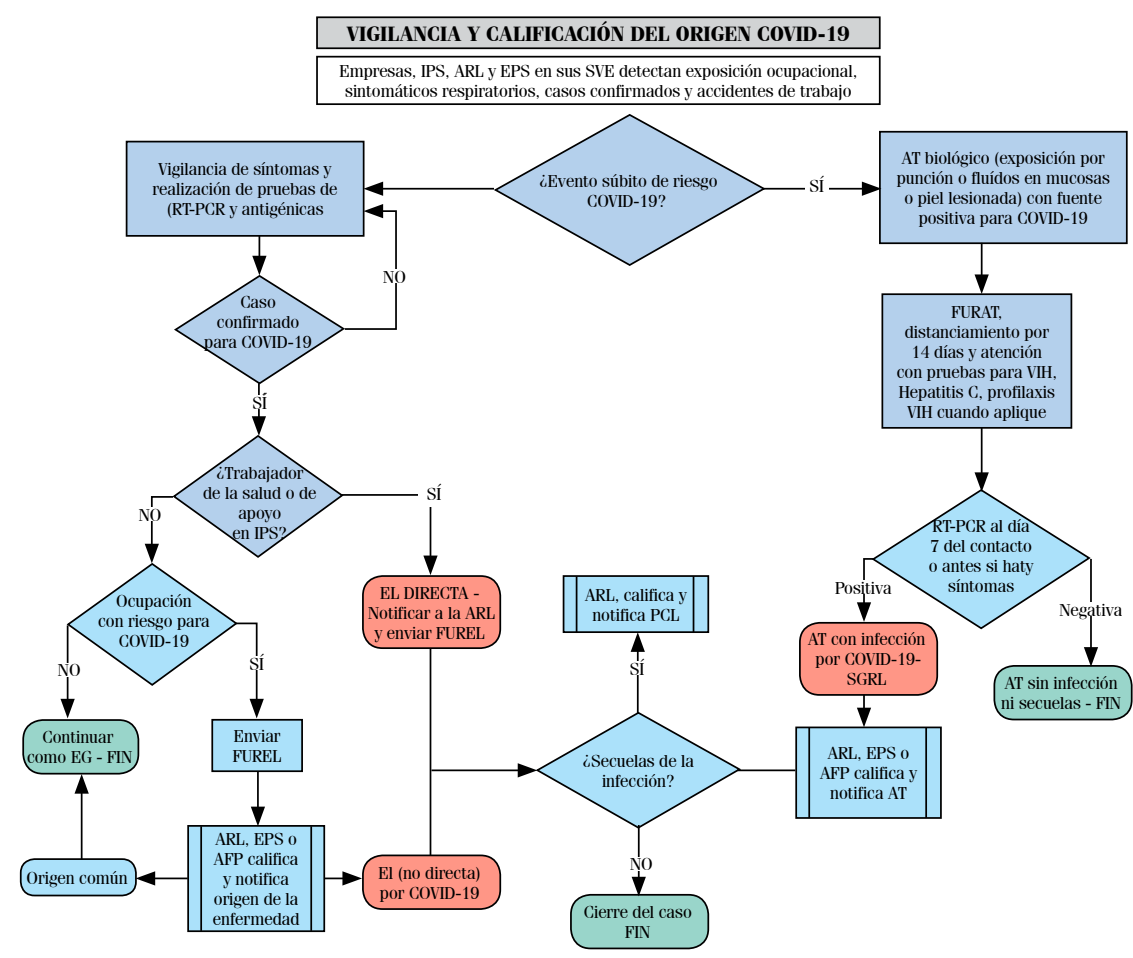

Fuente: Elaboración propia. 


\section{Conclusiones}

El derecho laboral en Colombia ha adoptado un sistema de calificación del origen de la enfermedad de tipo mixto, es decir, definiendo una lista de diagnósticos en una tabla de enfermedades que se presumen laborales, pero aceptando la calificación de cualquier otro diagnóstico, siempre y cuando se demuestre un nexo de causalidad entre los riesgos laborales y la enfermedad calificada.

Sin embargo, las tablas de enfermedades laborales en Colombia no han impactado significativamente el proceso de calificación, ya que las aseguradoras de riesgos laborales y juntas de calificación de invalidez han insistido en exigir a las partes interesadas aportar pruebas que demuestren la relación de causalidad, incluso cuando el diagnóstico hace parte de la lista de enfermedades laborales y la ocupación implica un riesgo inherente, situación que tendría que dar lugar a la presunción del origen laboral.

Esta carga probatoria, que indebidamente ha recaído en los trabajadores, ha encontrado alivio en el concepto "enfermedad laboral directa", que fue introducido por el Decreto 1477 de 2014, mediante el cual se avanzó desde la presunción del origen laboral, a su aceptación automática, para cuatro enfermedades, sin necesidad de calificación alguna.

Durante la pandemia por COVID-19 se evidenció la dificultad de los trabajadores de salud para acceder a las prestaciones del Sistema de Riesgos Laborales ante la necesidad de tener que someterse a una calificación que podría tardar varios meses, a pesar del contundente y claro riesgo de contagio. Dicha dificultad fue atendida por el Gobierno Nacional al incluir la COVID-19 dentro de la tabla de enfermedades laborales, además de otorgarle la categoría de enfermedad laboral directa en el sector salud.

Esta situación debería ser atendida por el Ministerio del Trabajo al momento de reglamentar la calificación del origen de enfermedades y accidentes dentro del proyecto de decreto que actualmente se encuentra en elaboración, facilitando el proceso de calificación de acuerdo con lo establecido por el legislador y la OIT para aquellas enfermedades y ocupaciones cuya relación ya ha sido demostrada desde la epidemiología, con lo cual se garantizarían derechos fundamentales de los trabajadores y se propiciaría un equilibrio financiero entre el Sistema de Salud y el Sistema de Riesgos Laborales. 


\section{Referencias}

Acosta, S. \& Cuellar, G.J. (2019). Identificación y análisis del concepto de presunción en el marco de la calificación del origen de la enfermedad en Colombia. (Trabajo de grado para optar el título de abogado, Universidad de Antioquia).

Instituto Nacional de Salud. (2020). Instructivo para la vigilancia en salud pública intensificada de infección respiratoria aguda asociada al nuevo coronavirus 2019 (COVID-19). Recuperado de http://www.ins.gov.co/Noticias/ Coronavirus/Anexo_\%20Instructivo\%20Vigilancia\%20COVID\%20v13\% 2031122020.pdf

Méndez, J. (2015). Fundamentos teórico-prácticos del proceso de calificación de origen, fecha de estructuración y pérdida de capacidad laboral en Colombia. (Trabajo de grado para optar el título de abogado. Universidad Libre).

Ministerio de Salud y Protección Social. (2020). Lineamientos para prevención control y reporte de accidente por exposición ocupacional al COVID-19 en instituciones de salud. Recuperado de https://www.minsalud.gov.co/salud/publica/ https://www. minsalud.gov.co/salud/publica/PET/Paginas/Documentos-tecnicos-covid-19.aspx PET/Paginas/Documentos-tecnicos-covid-19.aspx.

Ministerio de Salud y Protección Social. (2020). Lineamientos para el uso de pruebas moleculares RT PCR, pruebas de antígeno y pruebas serológicas para SARS-COV-2 (COVID-19) en Colombia. Recuperado de https://www.minsalud.gov.co/Ministerio/ Institucional/Procesos\%20y\%20procedimientos/GIPS21.pdf

Ministerio de Salud y Protección Social. (2020). Decreto 538 de 2020. Por el cual se adoptan medidas en el sector salud, para contener y mitigar la pandemia por COVID 19 y garantizar la prestación de los servicios de salud, en el marco de estado de emergencia económica, social y ecológica. Diario oficial 51283. Recuperado de https://dapre.presidencia.gov.co/normativa/normativa/DECRETO\%20538\%20 DEL\%2012\%20DE\%20ABRIL\%20DE\%202020.pdf

OSHA. (2020). Guidance on Preparing Workplaces for COVID-19. (PDF). Recuperado de https://www.osha.gov/Publications/OSHA3990.pdf 